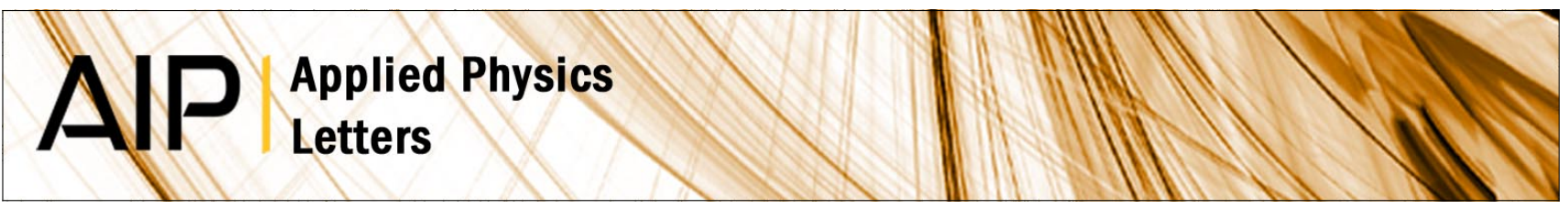

\title{
Effective reduction of fixed charge densities in germanium based metal-oxide-semiconductor devices
}

Shaoren Deng, Qi Xie, Davy Deduytsche, Marc Schaekers, Dennis Lin et al.

Citation: Appl. Phys. Lett. 99, 052906 (2011); doi: 10.1063/1.3622649

View online: http://dx.doi.org/10.1063/1.3622649

View Table of Contents: http://apl.aip.org/resource/1/APPLAB/v99/i5

Published by the American Institute of Physics.

\section{Related Articles}

Side-gate effects on the direct current and radio frequency characteristics of AIGaN/GaN high-electron-mobility transistor on $\mathrm{Si}$

Appl. Phys. Lett. 99, 163505 (2011)

Temperature dependence of current density and admittance in metal-insulator-semiconductor junctions with molecular insulator

J. Appl. Phys. 110, 083708 (2011)

Synthesis and electrical and magnetic properties of $\mathrm{Mn}$-doped $\mathrm{SnO} 2$ nanowires J. Appl. Phys. 110, 083907 (2011)

Effect of the Ti molar ratio on the electrical characteristics of titanium-indium-zinc-oxide thin-film transistors fabricated by using a solution process

Appl. Phys. Lett. 99, 161908 (2011)

Accurate characterization of organic thin film transistors in the presence of gate leakage current

AlP Advances 1, 042123 (2011)

\section{Additional information on Appl. Phys. Lett.}

Journal Homepage: http://apl.aip.org/

Journal Information: http://apl.aip.org/about/about_the_journal

Top downloads: http://apl.aip.org/features/most_downloaded

Information for Authors: http://apl.aip.org/authors

\section{ADVERTISEMENT}

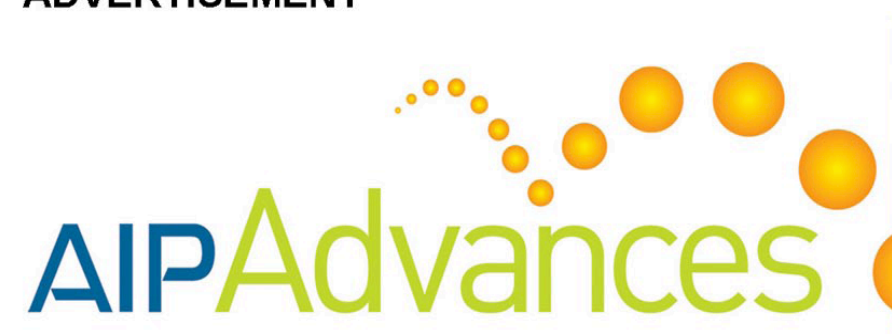

Submit Now

Explore AIP's new

open-access journal

Article-level metrics now available

Join the conversation!

Rate \& comment on articles 


\title{
Effective reduction of fixed charge densities in germanium based metal-oxide-semiconductor devices
}

\author{
Shaoren Deng, ${ }^{1}$ Qi Xie, ${ }^{1}$ Davy Deduytsche, ${ }^{1}$ Marc Schaekers, ${ }^{2}$ Dennis Lin, ${ }^{2}$ \\ Matty Caymax, ${ }^{2}$ Annelies Delabie, ${ }^{2}$ Sven Van den Berghe, ${ }^{3}$ Xinping Qu, ${ }^{4}$ and \\ Christophe Detavernier ${ }^{1, a)}$ \\ ${ }^{1}$ Department of Solid State Science, Gent University, Krijgslaan 281/S1, B-9000 Gent, Belgium \\ ${ }^{2}$ IMEC, Kapeldreef 75, B-3001 Leuven, Belgium \\ ${ }^{3}$ SCK-CEN, Boeretang 200, B-2400 Mol, Belgium \\ ${ }^{4}$ Department of Microelectronics, State Key Laboratory of ASIC and System, Fudan University, Shanghai \\ 200433, People's Republic of China
}

(Received 15 June 2011; accepted 15 July 2011; published online 3 August 2011)

\begin{abstract}
Metal-oxide-semiconductor capacitor was fabricated using in situ $\mathrm{O}_{2}$ plasma passivation and subsequent deposition of a $\mathrm{HfO}_{2}$ high-k gate stack on Ge. By extracting flat band voltages from capacitors with different equivalent oxide thicknesses (EOT), the effect of forming gas annealing (FGA) and $\mathrm{O}_{2}$ ambient annealing on the fixed charge was systematically investigated. The $\mathrm{O}_{2}$ ambient annealing is more effective than FGA as it reduced fixed charge density to $8.3 \times 10^{11}$ $\mathrm{cm}^{-2}$ compared to $4.5 \times 10^{12} \mathrm{~cm}^{-2}$ for at the same thermal budget and showed no degradation of EOT. Further, the distribution of fixed charges in gate stack was discussed in detail. (C) 2011 American Institute of Physics. [doi:10.1063/1.3622649]
\end{abstract}

High mobility Ge-based metal-oxide-semiconductor fieldeffect transistors (MOSFETs) are considered to be a promising substitute for current state of the art Si-based MOSFETs. ${ }^{1}$ The main problem for the application of $\mathrm{Ge}$ is the effective surface passivation before the deposition of the gate dielectric. ${ }^{2}$ Many attempts have been proposed to solve this problem such as introducing sulfurization, ${ }^{3} \mathrm{NH}_{3}$ plasma, ${ }^{4}$ thermal oxidation, ${ }^{5-7} \mathrm{H}_{2} / \mathrm{N}_{2} /$ Ar plasma, ${ }^{8}$ atomic $\mathrm{O},{ }^{9}$ ozone, ${ }^{10}$ and so on for the Ge surface passivation. Among all these techniques, the introduction of an interlayer (IL) formed by $\mathrm{GeO}_{2}$ gave the lowest density of interface states $\left(D_{i t}\right)$ and highest comprehensive performance. ${ }^{11-13}$ But at the same time, a large amount of fixed charge was introduced at the interface, which caused flat band voltage $\left(\mathrm{V}_{\mathrm{FB}}\right)$ shifting that has not been systematically investigated yet. ${ }^{6,14-16}$ Fixed charges of high density would cause lower mobility by strong coulombic scattering and shift of the threshold voltage. ${ }^{17,18}$ High temperature $\left(450^{\circ} \mathrm{C}\right)$ oxygen annealing was tried to improve the performance of metal-oxide-semiconductor (MOS) capacitor. ${ }^{19}$ Even though noticeable $\mathrm{V}_{\mathrm{FB}}$ shift appeared after annealing, the cost was serious degradation of equivalent oxide thicknesses (EOT). In this work, we present $\mathrm{O}_{2}$ annealing as an effective method to largely neutralize the fixed charges $\mathrm{GeO}_{2} \mathrm{IL}$ based MOS capacitors at relatively low temperatures.

Ge (100) wafers were first cleaned by a $2 \%$ HF solution for $1 \mathrm{~min}$ at room temperature and then rinsed by a large amount of de-ionized water for $5 \mathrm{~min}$ to remove the remaining $\mathrm{F}$ ions on the surface. Before the deposition of $\mathrm{HfO}_{2}$, the wafer was heated to $200^{\circ} \mathrm{C}$ in a homemade atomic layer deposition (ALD) system with a base pressure of $6 * 10^{-8}$ mbar. ${ }^{20}$ An in situ passivation of the surface of Ge wafer prior to the dielectric deposition was carried out by an $\mathrm{O}_{2}$ plasma treatment. ${ }^{21}$ Following this, $\mathrm{HfO}_{2}$ was deposited on the germanium oxide by plasma enhanced atomic layer deposition (PEALD) using Tetrakis-(ethylmethylamido) haf-

${ }^{\text {a)} E l e c t r o n i c ~ m a i l: ~ c h r i s t o p h e . d e t a v e r n i e r @ u g e n t . b e . ~}$ nium (TEMAH) and $\mathrm{O}_{2} .40 \mathrm{~nm} \mathrm{Pt}$ as top gate electrode formed by shadow mask and $20 \mathrm{nmTi} / 40 \mathrm{nmPt}$ as back contact were sputtered on the two sides of the device separately. Two types of post metal annealing (PMA) were conducted in a forming gas ambient and in an oxygen/nitrogen mixed ambient with $10 \%$ atomic concentration of oxygen. The thickness of the $\mathrm{HfO}_{2}$ was measured by x-ray reflectivity (XRR). The chemical composition of the passivated Ge wafer was characterized by x-ray photoelectron spectroscopy (XPS) using Al K $\alpha$ X-rays. Capacitance-voltage measurements were conducted using a HP 4192A impedance analyzer while the actual applied voltage on the MOS structure was read out by HP 3478A multimeter.

Completely oxidized Ge was widely considered to be the best IL with lowest interface states. ${ }^{6}$ To analyze the oxidation of the $\mathrm{Ge}$ in germanium oxide formed by $\mathrm{O}_{2}$ plasma passivation, XPS characterization was applied on the IL. To protect the surface from air, a $1 \mathrm{~nm} \mathrm{Al}_{2} \mathrm{O}_{3}$ capping layer was deposited on the passivated Ge by ALD prior to XPS measurement. In Fig. 1, the Ge $3 d$ peak

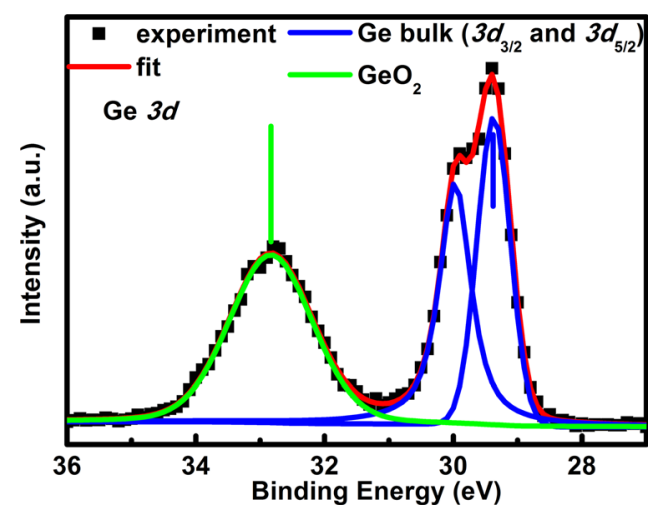

FIG. 1. (Color online) XPS Ge $3 \mathrm{~d}$ spectra for the $\mathrm{Al}_{2} \mathrm{O}_{3} / \mathrm{HfO}_{2} / \mathrm{GeO}_{2} / \mathrm{Ge}$ sample. 
TABLE I. Variety of $\mathrm{V}_{\mathrm{FB}}$ and $\mathrm{D}_{\mathrm{it}}$ after FGA or $\mathrm{O}_{2}$ annealing at 300 and $350^{\circ} \mathrm{C}$.

\begin{tabular}{lcccc}
\hline \hline Annealing ambient/temperature & $\mathrm{V}_{\mathrm{FB}} \mathrm{EOT}=1.3 \mathrm{~nm}$ & $\mathrm{~V}_{\mathrm{FB}} \mathrm{EOT}=1.8 \mathrm{~nm}$ & $\mathrm{~V}_{\mathrm{FB}} \mathrm{EOT}=3.1 \mathrm{~nm}$ & $\mathrm{D}_{\mathrm{it}}$ \\
\hline FGA $300^{\circ} \mathrm{C}$ & $0.5 \mathrm{~V}$ & $0.35 \mathrm{~V}$ & $0.2 \mathrm{~V}$ & $7 * 10^{11} \mathrm{eV}^{-1} \mathrm{~cm}^{-2}$ \\
FGA $350^{\circ} \mathrm{C}$ & $0.5 \mathrm{~V}$ & $0.35 \mathrm{~V}$ & $0.2 \mathrm{~V}$ & $4 * 10^{11} \mathrm{eV}^{-1} \mathrm{~cm}^{-2}$ \\
$\mathrm{O}_{2}$ annealing $300^{\circ} \mathrm{C}$ & $\mathrm{NA}$ & $0.55 \mathrm{~V}$ & $\mathrm{NA}$ & $6 * 10^{11} \mathrm{eV}^{-1} \mathrm{~cm}^{-2}$ \\
$\mathrm{O}_{2}$ annealing $350^{\circ} \mathrm{C}$ & $0.72 \mathrm{~V}$ & $0.70 \mathrm{~V}$ & $0.65 \mathrm{~V}$ & $2 * 10^{11} \mathrm{eV}^{-1} \mathrm{~cm}^{-2}$ \\
\hline \hline
\end{tabular}

shifted from 29.4 to $32.8 \mathrm{eV}$, indicating that the oxidation state of Ge is $4+$. Simultaneously, no obvious doublets in the fitting curve can be seen between the peak of Ge4+ and bulk Ge, which implies very limited existence of a suboxidation state of Ge. The XPS result of $\mathrm{Ge} 3 \mathrm{~d}$ indicates that $\mathrm{Ge}$ was completely oxidized by $\mathrm{O}_{2}$ plasma passivation and exhibited a $\mathrm{Ge}^{4+}$ oxidation state.

MOS capacitors experienced forming gas annealing (FGA) at 300 and $350^{\circ} \mathrm{C}$ and oxygen annealing at 300, 350, and $400^{\circ} \mathrm{C}$ were studied. Among the MOS capacitors after annealing, the one after $400^{\circ} \mathrm{C}$ oxygenic annealing, the results showed a $0.2 \mathrm{~nm}$ increase of EOT, then limiting further scaling. $\mathrm{V}_{\mathrm{FB}}$ and $\mathrm{D}_{\mathrm{it}}$ as a function of EOT after FGA or $\mathrm{O}_{2}$ annealing at 300 and $350^{\circ} \mathrm{C}$ without EOT degradation are listed in Table I. The two capacitors after $300^{\circ} \mathrm{C}$ FGA and $300^{\circ} \mathrm{C}$ oxygen annealing show relatively high $\mathrm{D}_{\mathrm{it}}$ (around $7 * 10^{11} \mathrm{eV}^{-1} \mathrm{~cm}^{-2}$ ), even though the $\mathrm{V}_{\mathrm{FB}}$ of the MOS capacitor after $300^{\circ} \mathrm{C}$ oxygen annealing shifted from 0.35 to $0.55 \mathrm{~V}$. Only the MOS capacitor after $350^{\circ} \mathrm{C}$ annealing has relative high $\mathrm{V}_{\mathrm{FB}}$ shift from 0.35 to $0.7 \mathrm{~V}$ and no degradation of EOT. Therefore, $350{ }^{\circ} \mathrm{C}$ annealing in $\mathrm{O}_{2}$ ambient was selected for further investigation. $\mathrm{C}-\mathrm{V}$ characterizations as illustrated in the Figs. 2(a) and 2(b) show the electrical properties of the MOS capacitors with $5.5 \mathrm{~nm}$ $\mathrm{HfO}_{2}$ on $\mathrm{n}$ type $\mathrm{Ge}$ after FGA and $\mathrm{O}_{2}$ annealing at $350{ }^{\circ} \mathrm{C}$ for 30 min. After $\mathrm{O}_{2}$ annealing, the stretch out of the $\mathrm{C}-\mathrm{V}$ curve is less than after FGA annealing while the EOT of these capacitors are both $1.8 \mathrm{~nm}$. Using the high-low frequency method, the calculated $\mathrm{D}_{\text {it }}$ after $350^{\circ} \mathrm{C} \mathrm{FGA}$ and $\mathrm{O}_{2}$ ambient annealed are $4 \times 10^{11} \mathrm{eV}^{-1} \mathrm{~cm}^{-2}$ and $2 \times 10^{11} \mathrm{eV}^{-1} \mathrm{~cm}^{-2}$ at $\mathrm{V}_{\mathrm{FB}}$, respectively. The voltage of the mid gap of the capacitor shifts from $0 \mathrm{~V}$ for FGA to around $0.5 \mathrm{~V}$ after $\mathrm{O}_{2}$ annealing. This shift is related to the large amount of fixed charges introduced during $\mathrm{O}_{2}$ plasma passivation or $\mathrm{HfO}_{2}$ growth. Bellenger's work showed that the density of this fixed charge was about $2-3 \times 10^{12} \mathrm{~cm}^{-2}$ in the case of a $\mathrm{HfO}_{2} / \mathrm{GeO}_{2}$ gate stack, ${ }^{6}$ i.e., in the range lower than $1 \%$ compared to the sur- face density of Ge (100). This is far below the detection limit of most physical characterization techniques, e.g., XPS.

The fixed charges could be present at the interface of $\mathrm{HfO}_{2} / \mathrm{GeO}$ or $\mathrm{GeO}_{2} / \mathrm{Ge}$, at the bulk of $\mathrm{GeO}_{2}$ or $\mathrm{HfO}_{2}$. Therefore, the $\mathrm{V}_{\mathrm{FB}}$ of the $\mathrm{Pt} / \mathrm{HfO}_{2} / \mathrm{GeO}_{2} / \mathrm{Ge}$ structure can be expressed as below

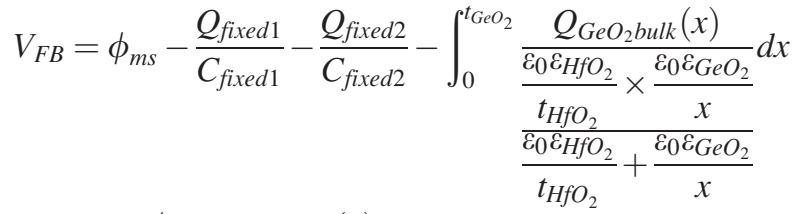

$$
\begin{aligned}
& -\int_{0}^{t_{H f O_{2}}} \frac{Q_{H f O_{2} b u l k}(y)}{\frac{\varepsilon_{0} \varepsilon_{H f O_{2}}}{y}} d y,
\end{aligned}
$$

where in the first three terms, $\phi_{m s}, Q_{\text {fixed } 1}, C_{\text {fixed } 1}, Q_{\text {fixed2 } 2}$, $C_{\text {fixed2 }}$ are the differences in work function between gate electrode and $\mathrm{Ge}$, the density and the capacitance of the fixed charge at the $\mathrm{HfO}_{2} / \mathrm{GeO}_{2}$ interface, and the density and the capacitance of the fixed charge at the $\mathrm{GeO}_{2} / \mathrm{Ge}$ interface, respectively. In the last two terms, $t_{\mathrm{GeO}_{2}}, t_{\mathrm{HfO}_{2}}, Q_{\mathrm{GeO}_{2} \text { bulk }}(x)$, $Q_{\mathrm{HfO}_{2} b u l k}(y), \varepsilon_{\mathrm{SiO}_{2}}, \varepsilon_{\mathrm{HfO}_{2}}, \varepsilon_{0}$ are the physical thicknesses of $\mathrm{GeO}_{2}$ and $\mathrm{HfO}_{2}$, the densities of the fixed charge in bulk $\mathrm{GeO}_{2}$ and bulk $\mathrm{HfO}_{2}$, the permittivities of $\mathrm{SiO}_{2}, \mathrm{HfO}_{2}$, and vacuum. $\mathrm{X}$ is the distance from the interface of $\mathrm{HfO}_{2} / \mathrm{GeO}_{2}$. $\mathrm{Y}$ is the distance from the interface of $\mathrm{Pt} / \mathrm{HfO}_{2}$. Here, the effect of $D_{i t}$ has been ignored due to the very low $D_{i t}$ $\left(2 \times 10^{11} \mathrm{eV}^{-1} \mathrm{~cm}^{-2}\right)$ compared to the density of the fixed charges in these MOS capacitors.

Each term of Eq. (1) will have a specific contribution to the total $\mathrm{V}_{\mathrm{FB}}$. To find out the distribution of the fixed charges and quantitatively evaluate the effect of $\mathrm{O}_{2}$ annealing and FGA on the fixed charges, three types of capacitors with 3.9, $5.5,13 \mathrm{~nm} \mathrm{HfO}_{2}$ were fabricated with the same processing as stated above, using $350^{\circ} \mathrm{C}$ annealing temperature. After $\mathrm{C}-\mathrm{V}$ characterization, it is found that due to the high quality passivation and $\mathrm{HfO}_{2}$, the $\mathrm{D}_{\text {it }}$ of the capacitors after FGA
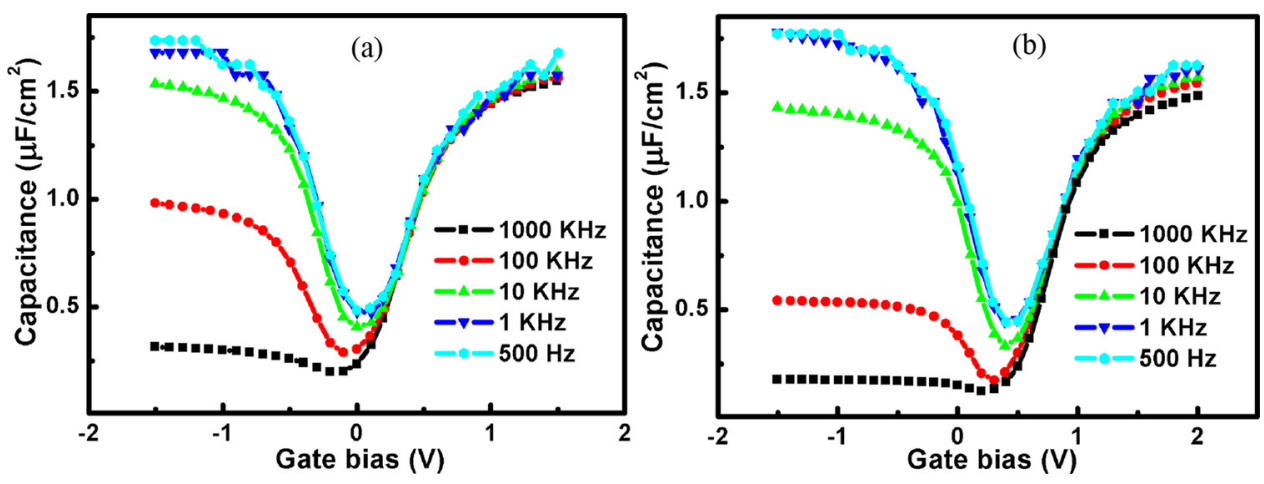

FIG. 2. (Color online) The C-V characterization of MOS capacitors with $\mathrm{Pt} /$ $\mathrm{HfO}_{2} / \mathrm{GeO}_{2} / \mathrm{Ge}$ after (a) $350^{\circ} \mathrm{C}$ FGA and (b) $350{ }^{\circ} \mathrm{C}$ oxygen ambient annealing. 


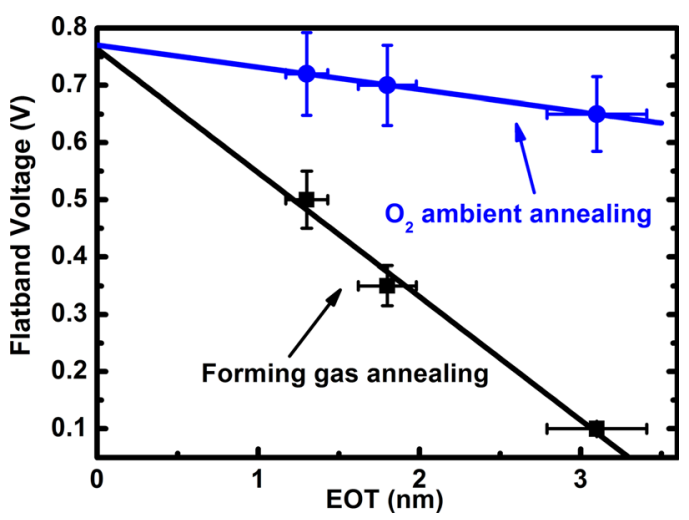

FIG. 3. (Color online) Flatband voltages vs EOT after $350^{\circ} \mathrm{C}$ FGA and oxygenic ambient annealing.

and $\mathrm{O}_{2}$ annealing do not vary with the EOT. The $\mathrm{V}_{\mathrm{FB}}$ was plotted in Fig. 3 as a function of EOT. According to the linear shape of the fitting line, the distribution of the fixed charges could be located at the $\mathrm{GeO}_{2} / \mathrm{Ge}$ interface, but not in the bulk $\mathrm{GeO}_{2}$ or at the $\mathrm{HfO}_{2} / \mathrm{GeO}_{2}$ interface. Otherwise, the integration of the third and fourth term in Eq. (1) would result in a non linear function of EOT which does not agree with the fitting. In addition, regarding the contribution from bulk $\mathrm{HfO}_{2}$ in the fourth term, we also fabricated $\mathrm{Pt} / \mathrm{HfO}_{2} / \mathrm{IL} /$ Si MOS capacitors for control samples and found that the $\mathrm{V}_{\mathrm{FB}}$ is also a linear function of EOT. The extracted density of fixed charges is below $5 \times 10^{11} \mathrm{~cm}^{-2}$. Accordingly, the fixed charges in the bulk of $\mathrm{HfO}_{2}$ are under the detection limit of electrical measurements as the ones in bulk $\mathrm{GeO}_{2}$. Therefore, the fourth term of the Eq. (1) can be ignored. Considering the first term in Eq. (1), we further studied the intercepts of these two fitting lines in Fig. 3. These intercepts on $\mathrm{Y}$ axis are both $0.77 \mathrm{~V}$, which implies that the work function of $\mathrm{Pt}$ on $\mathrm{HfO}_{2}$ is about $4.9 \mathrm{eV}$ which is consistent with the reported data. ${ }^{22}$ Thereby, the distribution of the fixed charges would not be at the $\mathrm{HfO}_{2} / \mathrm{GeO}_{2}$ interface. Otherwise the intercepts would not be the same and result in different effective work functions of $\mathrm{Pt}$, because the $\mathrm{V}_{\mathrm{FB}}$ will not be the function of EOT but the function of the equivalent oxide thickness of $\mathrm{HfO}_{2}$. Simultaneously, the very low CV hysteresis of $50 \mathrm{mV}$ also implies limited intermixing between $\mathrm{HfO}_{2}$ and $\mathrm{GeO}_{2}{ }^{23}$ Therefore, the interface of $\mathrm{HfO}_{2} / \mathrm{GeO}_{2}$ is probably intact. According to the above calculation and reasoning, the Eq. (1) can be consequently written as

$$
V_{F B}=\phi_{m s}-\frac{Q_{\text {fixed } 2}}{C_{\text {fixed } 2}}
$$

which only counts in the contribution of $\phi_{m s}$ and the fixed charges at the $\mathrm{GeO}_{2} / \mathrm{Ge}$ interface.

The negative slope of the fitting lines also elucidates that the sign of fixed charges introduced by using TEMAH as Hafnium precursor in ALD is positive. This agrees well with Sreenivasan's report on the sign of fixed charges in $\mathrm{Si}$ based MOS capacitor by using different types of Hf precursors in the ALD process. ${ }^{24}$ From the plot the fixed charge densities after two types of annealing were calculated indi- vidually by extracting the slope of the Eq. (2). The fixed charges density of the capacitor after FGA is $4.5 \times 10^{12}$ $\mathrm{cm}^{-2}$ while the density is $8.2 \times 10^{11} \mathrm{~cm}^{-2}$ after $\mathrm{O}_{2}$ annealing. This significant reduction of fixed charges can be interpreted by the assumption that $\mathrm{O}_{2}$ annealing introduces extra oxygen into the gate stack and reduce the number of the oxygen vacancies or Ge dangling bonds. Henkel et al. reported that only very thin Pt electrode with thickness of $5 \mathrm{~nm}$ could act as an assistant media in $\mathrm{O}_{2}$ annealing at $450{ }^{\circ} \mathrm{C}$ for $\mathrm{D}_{\mathrm{it}}$ reduction, but it was at the price of large compromising EOT. ${ }^{19}$ However, in our processing, the oxygen annealing still influences the performance of the MOS capacitor even when the top Pt electrode is $40 \mathrm{~nm}$. Of more importance, due to the lower annealing temperature in our process, the EOT is not affected, while both the $\mathrm{D}_{\mathrm{it}}$ and the density of fixed charges decrease significantly. This is consistent with slow growth rate of $\mathrm{GeO}_{2}$ in pure oxygen at $350^{\circ} \mathrm{C}$ reported in Ref. 6.

In summary, the $\mathrm{O}_{2}$ ambient annealing not only amends the $D_{\text {it }}$ of Ge based MOS capacitor but also effectively reduces the density of fixed charges located at the interface of $\mathrm{GeO}_{2} / \mathrm{Ge}$. Without compromising the EOT of the capacitors, the benefits of $\mathrm{O}_{2}$ annealing at $350^{\circ} \mathrm{C}$ suggest that it is a promising process to enhance the performance of Ge based MOS devices and offers the possibility for device scaling down.

The research leading to these results has received funding from the European Research Council under the European Union's Seventh Framework Programme (FP7/2007-2013)/ ERC Grant Agreement No. 239865.

${ }^{1}$ C. O. Chui, H. Kim et al., Tech. Dig. - Int. Electron Devices Meet. 2002, 437.

${ }^{2}$ M. Caymax, G. Eneman et al., Tech. Dig. - Int. Electron Devices Meet. 2009, 461.

${ }^{3}$ M. M. Frank, S. J. Koester et al., Appl. Phys. Lett. 89, 112905 (2006).

${ }^{4}$ Q. Xie, J. Musschoot et al., App. Phys. Lett. 97, 222902 (2010).

${ }_{5}^{5}$ A. Delabie, F. Bellenger et al., App. Phys. Lett. 91, 082904 (2007).

${ }^{6}$ F. Bellenger, M. Houssa et al., J. Electrochem. Soc. 155, G33 (2008).

${ }^{7}$ K. Kutsuki, G. Okamoto et al., App. Phys. Lett. 95, 022102 (2009).

${ }^{8}$ Y. Oshima, M. Shandalov et al., App. Phys. Lett. 94, 183102 (2009).

${ }^{9}$ P. Tsipas, S. N. Volkos et al., App. Phys. Lett. 93, 082904 (2008).

${ }^{10}$ D. Kuzum, T. Krishnamohan et al., IEEE, Electron Device Lett. 29, 328 (2008).

${ }^{11}$ C. H. Lee, T. Nishimura et al., Tech. Dig. - Int. Electron Devices Meet. 2010, 416.

${ }^{12}$ Y. C. Fu, W. Hsu et al., Tech. Dig. - Int. Electron Devices Meet. 2010, 432.

${ }^{13}$ X. F. Li, X. J. Liu et al., App. Phys. Lett. 98, 162903 (2011).

${ }^{14}$ C. O. Chui, F. Ito et al., IEEE Electron Device Lett. 25, 613 (2004).

${ }^{15}$ C. Mahata, M. K. Bera et al., Thin Solid Film 517, 163 (2008).

${ }^{16}$ J. D. Hwang, D. S. Lin et al., Thin Solid Film 519, 833 (2010).

${ }^{17}$ H. Y. Jin, and N. W. Cheung, IEEE Electron Device Lett. 29, 674 (2008).

${ }^{18}$ A. Dimoulas, P. Tsipas et al., Appl. Phys. Lett. 89, 252110 (2006).

${ }^{19}$ C. Henkel, O. Bethge et al., Appl. Phys. Lett. 97, 152904 (2010).

${ }^{20}$ Q. Xie, Y. L. Jiang et al., J. Appl. Phys. 102, 083521 (2007).

${ }^{21}$ Q. Xie, D. Deduytche et al., Appl. Phys. Lett. 97, 112905 (2010).

${ }^{22}$ D. Gu, S. K. Dey, and P. Majhi, Appl. Phys. Lett. 89, 082907 (2006).

${ }^{23}$ Q. Xie, D. Deduytsche et al., Electrochem. Solid-State Lett. 14, G20 (2011).

${ }^{24}$ R. Sreenivasan, P. C. McIntyre et al., App. Phys. Lett. 89, 112903 (2006). 